\title{
Article
}

\section{Aphasia and Spirituality: the feasibility of assessment and intervention using WELLHEAD and SHALOM}

Mumby, Katharyn and Roddam, Hazel

Available at http://clok.uclan.ac.uk/32885/

Mumby, Katharyn and Roddam, Hazel ORCID: 0000-0002-0637-1801 (2021) Aphasia and Spirituality: the feasibility of assessment and intervention using WELLHEAD and SHALOM. Aphasiology, 35 (7). pp. 925-949. ISSN 0268-7038

It is advisable to refer to the publisher's version if you intend to cite from the work. http://dx.doi.org/10.1080/02687038.2020.1752907

For more information about UCLan's research in this area go to http://www.uclan.ac.uk/researchgroups/ and search for < name of research Group>.

For information about Research generally at UCLan please go to http://www.uclan.ac.uk/research/

All outputs in CLoK are protected by Intellectual Property Rights law, including Copyright law. Copyright, IPR and Moral Rights for the works on this site are retained by the individual authors and/or other copyright owners. Terms and conditions for use of this material are defined in the policies page.

\section{CLoK}

Central Lancashire online Knowledge www.clok.uclan.ac.uk 


\section{Aphasia and Spirituality: the feasibility of assessment and intervention using WELLHEAD and SHALOM}

Katharyn Mumby* and Hazel Roddam ${ }^{\mathrm{b}}$

${ }^{a}$ New Pathways, Hemyock, Devon UK; ${ }^{b}$ School of Health Sciences, University of Central Lancashire, Preston UK

e-mail for the *corresponding author: kath@new-pathways.co.uk

Lead author ORCID https://orcid.org/0000-0002-4028-7400

Second author ORCID https://orcid.org/0000-0002-0637-1801

Twitter@HazelRoddam1 


\title{
Aphasia and Spirituality: the feasibility of assessment and intervention using WELLHEAD and SHALOM
}

\begin{abstract}
Background: Spiritual aspects of aphasia rehabilitation are poorly understood, though identified within adjustment. Existing spiritual health assessments have not been used with people with aphasia, and no structured program to facilitate intervention has been documented, despite acknowledgments that spirituality is important in health and wellbeing and distinct from quality of life and mental health.
\end{abstract}

Aims: Mixed methods were used to investigate the accessibility and acceptability of a spiritual health assessment (SHALOM) and WELLHEAD, a toolkit originated by Mumby for spiritual health assessment and intervention, using the religiously neutral dimensions of 'WIDE, LONG, HIGH and DEEP'.

Method: A Steering group (five people with aphasia) shaped the feasibility study cyclically, agreeing that 'Meaning and purpose' defined spirituality, and selecting SHALOM. WELLHEAD was modified collaboratively with the Steering group and Hospital Chaplain. A convenience sample of 10 people with aphasia (discharged from therapy) represented diverse aphasia histories, ages and religious backgrounds. Participants completed a two-hour session using SHALOM, the WELLHEAD toolkit and a feedback questionnaire within videorecorded interviews. Quantitative results from all three components were integrated with a qualitative thematic analysis in NVivo 11 including numerical and descriptive summaries verified by the participants, feedback interview transcripts and field notes with reflections. The thematic analysis was systematically and independently verified by a co-researcher. Feedback from participants was further verified by incorporating their comments from reviewing the overall findings.

Results: Quantitative and qualitative feedback evaluated the materials positively. Thematic analysis provided evidence of the accessibility, acceptability and positive impact of WELLHEAD irrespective of aphasia severity or aetiology, and religious background. 'Belief', 'Faith' and 'Religion' were disambiguated. 
SHALOM was also linguistically and cognitively accessible with communication support even for those with severe aphasia. Scores from WELLHEAD and SHALOM were compared and set into the context of wider standardisation of SHALOM, providing the first evidence of spiritual health measures in participants with aphasia.

Conclusions: This preliminary work lays foundations for spiritual assessment and intervention in aphasia. Establishing the psychometric properties of SHALOM and WELLHEAD in people with aphasia requires a larger sample. Additional study of intervention is proposed, with clear potential for wider application of WELLHEAD in diverse settings and populations.

Keywords: aphasia; spirituality; intervention; assessment; health; outcome

\section{Introduction}

Spirituality has been defined by consensus as 'the aspect of humanity that refers to the way individuals seek and express meaning and purpose and the way they experience their connectedness to the moment, to self, to others, to nature, and to the significant or sacred' (Puchalski et al., 2009, p.887). Within healthcare, spirituality is recognised as a separate domain from quality of life (Sawatsky, Ratner \& Chiu, 2005), but has received comparatively little attention from aphasiologists. Despite the need to establish more rigorous measurements of interventions and outcomes in spiritual terms (Nolan, 2014; McSherry \& Ross, 2010), it is already recognised that increased spirituality is related to better health (Campbell, Yoon \& Johnstone, 2010; Johnstone, Franklin, Yoon, Burris, \& Shigaki, 2008) and concerns resilience in the elderly (Martin, Distelberg, Palmer \& Jeste, 2015).

Aphasia carries a well-known negative impact on health-related quality of life (HRQoL) (Lam \& Wodchis, 2010) and on mental health manifesting as depression (Hilari, Needle \& Harrison, 2012) and anxiety (Morris, Eccles, Ryan \& Kneebone, 2017). Despite the established connection of spiritual health to mental health (Berk et al., 2015; Koenig, 2012, 2016) spirituality is a seriously neglected aspect of aphasia rehabilitation (Carey \& Mathisen, 2018; Mackenzie, 2016; Mumby \& Grace, 2019) 
with a lack of appropriate measurements and interventions in healthcare practice, standard approaches including 'talking therapies' being by nature inaccessible for people with communication difficulties. In Wray and Clark's (2017) systematic review and synthesis of qualitative findings about the long-term needs of people with communication difficulties post stroke, reference to spirituality is notable by its absence.

Previous work by the primary investigator (PI) concerning adjustment processes in aphasia post stroke (Mumby \& Whitworth, 2013) identified improvements in quality of life and a shift towards 'wholeness' involving spirituality. Grieving for loss, rationalisation and finding meaning characterised personal and emotional adjustment, but the spiritual mechanisms were not fully explored. Mumby subsequently originated WELLHEAD (Mumby, 2017) using a model first reported in Mumby and Hobbs (2017) with theoretical foundations which are described elsewhere aligning with Swinton's (2001) model of spirituality (Mumby \& Grace, 2019). Since the WELLHEAD prototype (described in Mumby, 2018) was devised, two further studies confirmed the importance of spirituality for people with aphasia. Laures-Gore, Lambert and Kruger (2018) used interviews and a questionnaire to derive themes from 13 individuals with a pre-existing diagnosis of 'mild aphasia'. They showed that their sample was predominantly 'religious' which makes it unwise to extrapolate their findings about a 'greater power' being 'a helper' 'in control of events' to people with non-religious spirituality. Mackenzie and Marsh (2018) interviewed eight individuals with 'expressive aphasia' and brought to light the presence of ambiguity as part of communication, identity and spiritual understandings: presenting a challenge for future assessment and intervention. Neither study specified the exact types of impairment within the samples, making it difficult to draw firm conclusions about generalisability. The acknowledged limitations to both studies reinforced the need for a systematic and spiritually diverse approach to spirituality with people who have aphasia. Moreover, Mackenzie's (2016) findings from interviewing allied health professionals (AHPs) in a stroke unit rehabilitation team (a speech and language therapist (SLT), an occupational therapist and a physiotherapist) confirmed the need for guidelines and resources for supporting dialogue about spirituality with those who have aphasia. 
Existing reviews of resources for spiritual health assessment and intervention (de Jager Meezenbroek, et al., 2012; McSherry \& Ross, 2010; Monod, et al., 2011) revealed two main candidates for use as a comparator assessment alongside WELLHEAD. The Spiritual Health and Life Orientation Measure (SHALOM, Fisher, 2010) developed from the Spiritual Well-being Questionnaire (Gomez \& Fisher, 2003) was described as the 'most promising' by de Jager Meezenbroek et al. (p.349), and has since undergone more standardisation (Fisher, 2016; Fisher, 2014, refers to 52 studies, using SHALOM with 41686 people from 27 countries). The WHO SPRB - BREF (Skevington, Gunson \& O'Connell, 2013) (developed from the longer WHOQOL SPRB (Fleck \& Skevington, 2007)) also had detailed psychometric evaluation, but neither assessment had prior use with people with aphasia. There were no reports of interventions designed for people with aphasia, and no evidence of the adoption of existing frameworks and screening tools with this population (Mathisen \& Threats, 2018).

The current study aimed to determine firstly whether a standard spiritual health assessment was suitable for people who have aphasia, and secondly how they can explore, evaluate and move forward with their spirituality using WELLHEAD. The wider aim was to ensure that spiritual aspects of adult healthcare provision can be made accessible to people with communication impairments so that they are as accessible as possible to all.

\section{Materials and Methods}

A feasibility study of the WELLHEAD resources was conducted in a UK hospital outpatient setting in accordance with Health Research Authority approval (IRAS id 216799 https://www.hra.nhs.uk/planning-and-improvingresearch/application-summaries/research-summaries/aphasia-and-spirituality-toolkitpilot-study-version-1/). A Steering group for the project consisted of five people with aphasia (previously discharged from SLT) who had consented to contact about aphasia research post-discharge, and subsequently volunteered to join the group. Regular Steering group meetings using 'Total communication' were chaired by the PI, an SLT, throughout the project with the support of hospital volunteers (trained communication partners) who helped take 'aphasia friendly' notes. The Steering group reviewed the 
assessments in detail to determine their suitability for people with communication difficulties, finding SHALOM more accessible than the WHOQOL-SRPB BREF (Mumby, in review).

The SHALOM questionnaire comprises numerical scores in four domains (Personal, Communal, Environmental and Transcendental). Participants rate 20 items on a scale of 1-5 according to the two parameters of 'spiritual ideals' and 'lived experience' SWBQ (see Fisher, 2010 p.109) giving overall scores and an indication of spiritual dissonance (where mean ideals and lived experience differ by a value of 1 or more).

The WELLHEAD toolkit (Mumby, 2017) is a structured resource for promoting spiritual health using language that avoids religious bias, where spirituality is concerned with 'meaning and purpose' in life. WELLHEAD supports conversation and reflection using a range of pictures (mostly photographs), word boards (short lists of key words) and starter questions (also available in written form). The resources are organised in four dimensions (WIDE, LONG, HIGH and DEEP) progressing from the most neutral terms to more specific terms as directed and chosen by the participant encouraged by the interviewer. Each dimension incorporates self-evaluation via patient reported outcome measures (PROMs) using a scale of 1-10, using the discussion and scores to inform goal-setting ('Next Steps'). The Steering group reviewed WELLHEAD, modified the toolkit prior to its use and approved the working definitions of spirituality, religion, faith and belief as incorporated within word boards.

The focus of each dimension is summarised in Figure 1.

Insert Figure 1 about here

\section{Recruitment}

Following locally agreed governance protocols, within the last five years participants had all consented at discharge to be listed on the aphasia database of the SLT department (excluding people with challenging behaviour, dementia or apraxia as their primary diagnosis rather than aphasia). Ten adults with aphasia were recruited over a six-month period focusing initially on those with most recent assessment details, followed by candidates discharged longer ago. Basic participant details were extracted 
from their archived SLT notes to avoid additional questioning and testing. This information and the initial contact process excluded any who were acutely or terminally ill, had a known mental health diagnosis, or were seeking help for low mood, to protect them from possible distress. Out of 32 people on the database, 10 were excluded due to potential conflict of interest from participating in activities post discharge (part of the project Steering group, part of an Expert Trainers program or voluntary services in the hospital). Three people who had strokes several years ago could not be contacted. The remainder were approached about the study by telephone or email according to their communication preference recorded on the database. Individuals were sent full written details of the study before deciding about participation.

One was excluded because her aphasia had resolved. Six further people declined to participate (two were ill, four unable to attend due to work commitments). Amongst those who showed willingness to participate two withdrew due to relocation. Ten participants (mean 7 months, range $2-18$ months post-discharge) were successfully recruited to the study. At attendance, aphasia-friendly consent for participation and recordings was overseen by a research nurse.

Participant demographics, aetiology and aphasia characteristics known at recruitment are summarised in Tables 1 and 2. The Therapy Outcome Measures (TOMs, Enderby \& John, 2015) at discharge from SLT were judged to represent participants' current level by the PI. All but 'YELLOW' were right-handed.

Insert Table 1 about here

Insert Table 2 about here

\section{Quantitative and Qualitative Data collection}

Participants attended a two-hour research session at the hospital, in a separate building used for training. One participant with global aphasia (RED) chose to have his wife present throughout as an observer. Refreshment breaks were timed according to personal needs. Optional additional support from the hospital chaplain was offered, comprising further signposting and appropriate follow-up according to individual preferences. 
The PI administered SHALOM (supporting participants by reading the sentences aloud and helping them focus on the task) followed by a semi-structured interview using the WELLHEAD toolkit. The administration of the toolkit incorporated choices to ensure materials matched the person's level of communication, sensory perception and cognition (memory and attention). The toolkit focused on promoting self-assessment and helping people to explore potential next steps. To reduce bias from the PI's notes, responses were also video-recorded and forms completed and checked with participants, helping to answer questions about 'why' and 'how' responses were given. A summary of the WELLHEAD findings was completed contemporaneously and verified by participants who were given full details of their assessment findings.

After participating in SHALOM and WELLHEAD, participants completed a feedback questionnaire (Appendix A) within a semi-structured interview. Their responses were summarised and read back to check for accuracy. The WELLHEAD interviews and feedback interviews were all videoed.

\section{Verification}

The data collection incorporated multiple checks during and after the interviews to reduce ambiguity and ensure accuracy. Individual findings were shared with participants via post or email according to their preference. Participants were invited to attend two optional feedback sessions with the support of Steering group members, to review the overall anonymised results for accuracy and generalisability via shared reactions. Confidential one-to-one liaison concerning specific results was provided by email with prior consent, and in a limited way in private one-to-one conversations at the feedback sessions. Participants were encouraged to take a role in wider dissemination (contribution to conference presentations, feedback to local stroke-related groups, input into drafting papers where feasible), as exemplified in Mumby (2019).

Field notes included spontaneous feedback offered after the individual sessions, feedback concerning onward chaplaincy referral of two participants, and notes from the two optional feedback sessions. All field notes and reflections were incorporated into the analysis to identify and acknowledge varying interpretations. 


\section{Analysis}

The video recordings of the feedback interviews were transcribed (including use of gestures and alternative methods of communication where applicable) and combined with the other participant data preserving anonymity (via colour names for participants). The interview data, research field notes and qualitative feedback were subject to a systematic thematic analysis (based on constructivist epistemology) in NVivo 11 (according to methods already used in Mumby and Whitworth, 2012, 2013). To minimise bias from a single individual, the PI's initial coding in NVivo 11 was verified and weighed independently by a co-researcher competent in qualitative methods but without prior experience in aphasia and spirituality research (Roddam). The researchers engaged in discussion to incorporate alternative perspectives and identify any areas where multiple interpretations were equally valid.

\section{Process and justification for verification sample}

To demonstrate an appropriately transparent and rigorous verification of the initial data coding, a systematic selection of $20 \%$ of the transcripts was made, ensuring a minimum of 3,100 words. Selections included complete Question:Response exchanges and covered all questions, systematically across all participants. All extracts were clearly labelled within the verification sample (3,149 words) to enable coding verification. Firstly, the face validity of the allocated codes was checked by the coresearcher. Secondly, both researchers agreed to reorganise the nodes into a meaningful tree structure, subsequently undertaken by the PI: giving key themes of impact, acceptability and accessibility. The face validity of the new nodes was then cross checked by the co-researcher, prior to further in-depth analysis. Three phases of analysis were conducted:

\section{Phase 1}

The Feedback interviews were analysed and verified as described above, using transcripts in combination with reflective field notes, the numerical scores and written records (including scores from SHALOM and WELLHEAD, and the feedback questionnaires). Information about the usage of component parts of WELLHEAD was also gathered. 
Phase 2

A second phase of analysis incorporated summary findings from WELLHEAD which had already been verified by each participant. Additional review by the coresearcher ensured the thematic analysis was robust. Feedback concerning onward chaplaincy referral of two participants was also incorporated. Quantitative findings from WELLHEAD and SHALOM were compared (using Pearson's test where applicable). The primary focus of this phase was to ascertain the detailed nature of the impact of the resources.

Phase 3

The third phase of analysis used additional transcription of the WELLHEAD interviews to provide more extensive thematic exploration concerning individual spirituality in comparison with the summaries. (An example of a Phase 3 narrative may be found in Mumby, 2019). This description of Phase 3 here is important as it gives appropriate fuller context to the participant feedback.

This paper focuses on the findings from Phase 1 and findings about impact from Phase 2 rather than the in-depth exploration of individuals' spirituality.

\section{Results: Phase 1}

There was a diverse range of participants as shown in Tables 1 and 2. Four people had aphasia from stroke, but other aetiologies included traumatic brain injury, haematoma, brain tumour, dementia, with a range of co-morbidities including hemianopia. Participant ages ranged from 32 -87 years; mean 62.8. There was a wide range of time post-onset or post-surgery: 6 - 48 months; mean 21 months. Aphasia severity ranged from severe to mild (TOMs impairment 1- 4.5; mean 3.3).

The WELLHEAD interviews revealed the wide range of religious backgrounds of participants as shown in Table 3 .

Insert Table 3 about here 
There were different emphases even in participants who identified with the same religion, concerning value judgements and the degree of commitment.

All participants completed SHALOM and WELLHEAD and the feedback questionnaire, and as part of WELLHEAD they self-scored their spirituality and set goals (practical next steps), irrespective of age, aphasia severity and type and religious orientation. (Exploring how people with aphasia construe their spirituality was not the primary purpose of this paper, but a brief summary is given below to provide context as part of Phase 2 results). Three main themes of acceptability, accessibility and impact emerged from the thematic analysis, providing a framework for examining the findings. The questionnaire findings summarised in Figure 2 show strong positive feedback about the session overall (examined in more detail using the qualitative interview analysis).

Insert Figure 2 about here

\section{Acceptability}

The materials and the session were perceived acceptable in terms of personal viewpoint and values, emotional status and privacy.

\section{Harmony}

Despite having varied religious standpoints, all participants found the WELLHEAD materials aligned with their personal views and values (see Table 3), perhaps because there was flexibility and participants could select and use their preferred terminology.

CYAN: with the questionnaire at first I thought "oh no, a bit lightweight - let's get it over with", but yours was much more...open ....unconditional. It allowed me to think things through on my own terms. Allowed me to reflect on meaning and purpose. I think you've done a pretty good job

The definitions of Belief, Faith and Religion within WELLHEAD word boards (shown in Table 4) were confirmed as being acceptable according to all the participants (in keeping with the Steering group). 
Insert Table 4 about here

In sharing diverse life stories as part of the LONG dimension, the broad acceptability of the approach was confirmed. Participants shared how they developed religiously and spiritually, including change following stroke or other illness. They also shared an assumption that chaplains might have a specific religious agenda rather than accommodating a broad spectrum of viewpoints. Participants' willingness to continue what had been started in the session also indicated harmony with their experience.

\section{Comfort}

The feedback showed the interview took the right amount of time, was flexible enough, ended before fatigue set in, and allowed real engagement with the subject matter. Participants were all comfortable with the content of the pictures and words, though different participants found different components helpful, confirming the need to offer choice. They all confirmed nothing was uncomfortable. One participant's comment underlined the atmosphere of mutual trust:

YELLOW: I think I would have let you know.... if I had been (uncomfortable)

\section{Emotional Reactions}

Participants found it hard to identify the 'worst part' of the session. Several confirmed that it was challenging when emotions came to the surface. Eight of the participants were tearful or near to tears at some point in the interview, usually when reflecting on trauma, or uncovering personal feelings of guilt, shame or regret. The PI endeavoured to acknowledge and respect their feelings, sensitive to anything too distressing. The video was paused if they wished, while offering reassurance about sharing such emotions, until the participant chose to continue. In particular, the older men found exchanges quite personal and were unused to experiencing the emotions that arose:

KM: $\quad$ was there a worst part?

MAGENTA: no feeling I couldn't com com...it helped (circular gesture in air with pen)...couldn't things...couldn't tell.... what things...couldn't (puts pen down 
and leans back). What was the worst part (brings hands up as if grasping towards chest) being unable to to (sharp intake of breath)...do my feelings (turns to $\mathrm{KM}$ )

KM: $\quad$ (nods) being unable to express your feelings

MAGENTA: yeah (nods and wipes nose)

$\mathrm{KM}: \quad$ to me?

MAGENTA: $y u p$

KM: $\quad$ yeah

MAGENTA: and me (smiles at KM and laughs)

However, participants all stated that they felt better by the end of the session, and they confirmed the emotional connection was an important part of their exploratory process.

\section{Accessibility}

There was evidence for WELLHEAD being accessible in terms of language, sensory and cognitive skills, demonstrated in the wide range of impairments and aetiologies represented, some of which were progressive such as logopenic aphasia and incurable glioma (Table 2). Sensory impairment, such as hemianopia did not prevent the use of the picture materials or the value attributed to attempts at reading (ORANGE). Hearing loss was not an issue in the quiet interview environment, though MAGENTA misheard occasional words. The overall experience confirmed the benefit of providing visual and auditory sources of the same subject matter. Subthemes about accessibility will be explored in turn:

\section{Communication support}

WELLHEAD was consistently endorsed for supporting communication:

PURPLE: um...I think the pictures were.....were helpful to start with yeah (gestures to and fro with hand) and then to look through the the the phrases

Participants recognised the need for support, and shared exploration was valued:

KM: $\quad$ yes. So you wouldn't want to do it on your own

BLUE: $\quad$ no. I could not do on my own 
Language complexity.

All references to 'hard words' concerned SHALOM (e.g. 'Oneness') rather than WELLHEAD which was associated with ease of language processing. Participants all found the questions easy to understand, and the word boards supportive, helping to keep track of the conversational topic.

\section{Cognitive complexity}

Some topics were perceived to be conceptually demanding even when the words used were found simple enough:

YELLOW: No because.... I don't... think very well any more. So... every time I have to think...of what you've been talking about... and try and answer the question you're trying to pose..... it is it's incredibly difficult

Participants valued introduction of the ideas, some of which were unfamiliar and difficult to tackle without help, particularly in the context of severe aphasia.

RED: um..um Best part... ideals

KM: Ideals.

RED: yes

KM: $\quad$ So do you mean ideas (writes) or ideals (writes and draws on feedback sheet)? So ideas is like the thoughts.. and ideals is like the ..the top goal (gestures on top shelf)

RED: $u m$

KM: which one do you mean? (points to words)

RED: points to 'ideas'

$\mathrm{KM}$ ideas

RED: yes

KM: $\quad$ so it gave you some ideas

RED: yes 


\section{Impact}

The study was not designed to measure change over time, but participants identified several aspects of the impact of the session: facilitating rationalisation; catalysis of change; and perceived benefit.

\section{Rationalisation}

Participants found WELLHEAD helped them identify and reflect on aspects of their spirituality. This was a new departure for some, and for others, the first opportunity to rationalise their spiritual experience since the stroke. Facilitation of rationalisation was crucial as participants recognised aphasia had restricted the mind's ability to process verbally.

PURPLE: the whole.... story I suppose (gestures forwards with hand palm towards herself), sort of sort of....It brings you out (fingers on chin, looking upwards) sort of makes you think about everything (single handed circular gesture) that maybe you've you haven't thought about, to be honest with you

\section{Catalysis}

Half the participants felt their 'Next Steps' would lead to change, and 90\% wanted to continue to reflect on what had been started. (Themes from Next Steps will be summarised in Phase 2).

Two participants (BLUE and GREY) accepted the offer of chaplaincy followup, feedback from which will also be outlined in Phase 2. A further participant (MAGENTA) planned to seek follow-up with a local vicar. One participant (BLUE) sensed the potential benefit of using WELLHEAD within a group where discussions would help crystallise people's thoughts and feelings.

\section{Perceived benefit}

There was widely reported positive impact with life changes being initiated. At the end of the WELLHEAD interview the participant with the most severe aphasia (RED) spontaneously volunteered 'Well done', with others affirming the approach. 
KM: was was it helpful to you, d'you think?

ORANGE: yes (nods) all yes

KM: $\quad$ and...d'you think it is..is it general enough (arching global gesture with one hand)

ORANGE: (pause) yes (nods) it the the yes

KM: did you feel like I was steering you down one direction (gestures with two palms together going forwards)... and you wanted to go another way (gestures one hand going off to the side)

ORANGE: no no.

$\mathrm{KM}: \quad$ no

ORANGE: ssssssss (gestures speech coming from his mouth) yes

KM: $\quad$ so you could say the things you felt (nods)

ORANGE: yes (nods, then does 'thumbs up' sign)

KM: that was good

ORANGE: yes

KM: yes.. well... Thank you very very much

ORANGE: ahh (leans forward smiling and clasps KM's shoulder)

CYAN: $\quad m m$ (leans back) I think sometimes...when you do something like this erm... because it's it ha it has similarities to a life review (looks down at hands)

KM: (nods)

CYAN: um it you've got to let it marinade

KM: (smiles)

CYAN: and sometimes you think 'ah!' (lifts hand together in shape of grasping a small ball)

KM: (nods and readies pen)

CYAN: (opens hands out twice) that that brings something up that I didn't know

All but two people confirmed their readiness to continue exploring their spirituality along similar lines, underlining the benefit perceived. RED was unsure about further exploration. Bearing in mind that at the outset he ascribed the minimum importance to both religion and spirituality according to SHALOM, this indecision was not necessarily negative. CYAN said he had 'no need' to do more in a similar way but he had 'enjoyed the process'. During the feedback sessions (which four participants 
chose to attend, though one was prevented by illness) participants expressed their positive support for WELLHEAD as they felt it had helped them.

ORANGE invited his wife to attend the general feedback session, at which he chose to share his own aphasia-friendly transcript summary with her privately. She told the PI how important this sharing was, because global aphasia had prevented him expressing such thoughts and feelings with her since the stroke. They both shed tears with the PI after the end of the session, and ORANGE's wife expressed gratitude at the revelations (noted verbatim with consent), offering them a new joint understanding:

ORANGE's wife: It helps me understand where he has been...His aphasia is multilayered.....This is important as a way of moving forward...so now we get on with what we've got

A numerical record about the frequency of use of each picture was kept as a rationale for modifying future versions of WELLHEAD. Participants were satisfied with the content and welcomed the combination of choice from pictures and from words in the word boards.

\section{Feedback specific to SHALOM}

SHALOM had no prior use with people with aphasia, but the study showed that they found it manageable providing communication support was available.

Acceptability of SHALOM

In terms of the main themes, SHALOM was felt to be acceptable for all participants in terms of their personal viewpoint and values. The structure of SHALOM allowed participants to score their ideal conditions for spiritual health, including low importance for aspects that did not reflect their own views. The two supplementary questions about the importance of religion and spirituality provided valuable context to the 20 core items. Several participants commented during the questionnaire that an item had little relevance for them, so the PI explained about giving a low score for 'ideal for spiritual health' to give a context for interpreting a low score for 'lived experience'. (For example, RED's atheism was reflected in his low scores for both the importance of 
religion and spirituality, and his mean scores of 2 for Transcendental reflected his equally low ideals and lived experience as shown in Table 6 within Phase 2 below. The four participants who scored ' 1 ' (low importance) for 'religion' also had low Transcendental scores compared with other domains even in those who scored 'spirituality' as comparatively important).

One participant (CYAN) commented that he found parts of the questionnaire 'monotheistic' as he preferred to consider 'gods' rather than 'God'. He also annotated his response form to elaborate, as shown in italics: Worship of the creator:

'Enlightenment?'; Oneness with God: 'Theistic approach'; Peace with God: 'Peace with self'; Joy in Life: 'Depends on situation'; Prayer Life: 'Meditation/attitude'. Nevertheless, he felt no barrier to completing the assessment on his own terms.

\section{Accessibility of SHALOM}

Participants all welcomed communication support offered by the PI, which included: covering up lines below the one in question, concurrent reading aloud of the stimulus phrases, repetition of instructions if there were lapses in concentration, provision of the forms on yellow paper and with large font, checking validity at the time by recap and summaries, and slow pace (though the assessment was still feasible within 30 minutes). SHALOM was less suitable for people with severe aphasia. More able participants used their own strategies to help them complete the questionnaire. For example, CYAN used a piece of paper to cover up questions on the questionnaire below the one being answered. He was the only participant who undertook the questionnaire with minimal prompting. Two items: 'a sense of magic in the environment' and 'harmony with the environment' were noted by RED and ORANGE respectively as being hard to process. BROWN commented that it would help to have a practice item to score before starting.

Of all the participants, RED found SHALOM most difficult to complete owing to his very severe aphasia. The PI provided a significant amount of communication support, and scores required double-checking to ensure they reflected his intentions. Overall there was a sense that SHALOM would not be suitable for people with aphasia unless they were provided with an interview setting giving communication support. 


\section{Impact of SHALOM}

The impact of SHALOM was perceived largely as 'scene-setting'.

BROWN: Once you've got that (brief gesture with two hands from sides of head going down in parallel towards SHALOM questionnaire sheet)..then it takes you into there (brief gesture with two hands from sides of head going down in parallel towards WELLHEAD) then you know where you're going (leans on elbow)

As SHALOM was always administered first it is difficult to determine the extent to which it may have shaped subsequent discussions. Participants valued having a score to measure change and potentially make comparisons with other people. Scores of the importance to participants of religion and spirituality were useful for subsequent discussions, and for some it appeared to be the first time they had considered these aspects separately (in common with the experience of Steering group members, see Mumby, in review). The content of the domains was covered in WELLHEAD more fully according to personal preferences, and the comparative findings will be outlined within the Phase 2 results which follow.

\section{Results: Phase 2}

\section{Chaplaincy feedback}

Phase 2 incorporated general feedback from the chaplain who accepted onwards referral of two participants. He reported a detailed discussion with PURPLE in which he was able to suggest "ways to move forward in regard to her bereavement and current personal issues and choices'. PURPLE had 'appreciated the opportunity to talk these matters through with an independent person'.

The chaplain reported that he had a very detailed discussion with GREY 'about the loss of his elder brother, (name) over 50 years ago', something that he remembered every day since the tragedy with a difficult impact on family dynamics over the years. He spoke to them about the nature of unresolved grief and whether to consider bereavement counselling, offering onward referral to a specialist service. A direct re-referral for further SLT was also made as GREY and his wife felt uneasy about self-referral. 
Neither participant above received spiritual support from the chaplaincy during their previous contact with the health service, probably because their needs were not identified, so a referral was not made. Overall the chaplain stated it had been ' $a$ privilege to support the patients as out-patient referrals and give them signposts for their respective spiritual journeys'.

\section{Scope of WELLHEAD}

The WELLHEAD interviews drew out a wide range of issues pertaining to spirituality, confirming the scope of their impact. Providing context for the participant feedback in Phase 1, content from the participant-verified WELLHEAD summaries has been drawn together. The WIDE dimension showed the importance of positive connection for wellbeing, including small groups, family and friends; respect for and appreciation of the environment (or via the arts). Some felt more connected as time passed compared with immediately after becoming aphasic, whereas others still felt disconnected from previous relationships and, to a lesser degree, from the environment.

The LONG dimension revealed participants' sense of being on a personal life journey in which they sought meaning and growth through pivotal moments, change, and healing. Coming to terms with the past was gradual but important for new spiritual growth and habits.

Within the HIGH dimension, participants emphasised the personal experience of the transcendent, changing perspectives on religion, belief and faith going hand in hand with coming to terms with their aphasia. Hope and trust within the context of powerlessness, mystery and the unknown were recurrent themes.

The DEEP dimension was perhaps the most challenging one. Participants identified issues of low self-worth and learning to love the new self, with difficulty expressing strong emotions. They recognised guilt and shame and the need for forgiveness offering a sense of freedom. Some catharsis was found in interactions, and in letting go of activity to reflect or just ' $b e$ '.

The principles behind participants' 'Next Steps' were complex and varied. Overall, they combined reflecting and changing from within, with accepting help from 
others (particularly with words), and they acknowledged the transcendent to varying degrees. Many participants looked outwards altruistically and creatively, but also identified a need for self-preservation. They sought adjustment to increased dependency via letting go of unhelpful perceptions to enable living fully in the present with meaning and purpose for the future.

The rich summary findings outlined above provided evidence that WELLHEAD had appropriate scope and was feasible to use. The self-scores from WELLHEAD (Table 5) are shown with those from SHALOM (Table 6). WELLHEAD scores ranged from 3-10, showing that participants all felt they had moved some way towards where they wanted to be spiritually (none scored lower than 3) with an overall mean score of 7.55. SHALOM scores ranged from 1-5, overall ideal mean 4.19 and SWBQ 3.86.

Insert Table 5 about here

Insert Table 6 about here

\section{Findings from SHALOM and WELLHEAD}

There was no clear relationship between severity of aphasia or time post-onset and WELLHEAD or SHALOM scores. Overall SHALOM acted as a 'temperature reading' of spiritual health whereas WELLHEAD acted as a spiritual 'life review' with goal-setting.

SHALOM showed that participants had polarised perceptions of religion, all but one scoring at the extremes ( 1 or 5$)$ when rating its importance (see Table 6$)$.

Participant scores of the importance of spirituality showed the greater variation and larger range, showing that participants discriminated between spirituality and religion. For three participants (GREEN, PURPLE and BROWN) spirituality was important even though religion was of very low importance. The four participants for whom religion was particularly important (ORANGE, CYAN, BLUE, GREY) also perceived spirituality as important, and gave high scores in the transcendental domain. 
Measurements from SHALOM for the people with aphasia were compared with other populations in a preliminary way due to the small sample size. Indications were that the participants with aphasia had higher mean scores in each domain than acutely ill cancer or renal patients, as reported by Fisher (2016), summarised in Appendix B.

None of the participants had dissonance in their overall scores (a difference of 1 or more between their ideal score and their lived experience, but PURPLE's ideal Transcendental score was very low, so the minimum score for lived experience would not generate a difference of 1 . GREEN and BLUE showed dissonance within selected domains. Overall 15\% of participant scores (6 of 40) showed dissonance, particularly in the Personal domain (shown in bold in Table 6). The rates of dissonance were: Personal domain $(n=3,30 \%)$, Communal domain $(n=1,10.0 \%)$, Environmental domain $(n=1$, $10 \%)$, as well as the Transcendental domain $(\mathrm{n}=1,10 \%)$, all higher rates than a study of oncology patients (Riklikiene, Kaseliene, \& Fisher, 2018: which indicated 'limited spiritual dissonance' in the Personal domain $(\mathrm{n}=20,11.7 \%)$, Communal domain $(\mathrm{n}=$ 12, 7.0\%), Environmental domain $(n=6,3.5 \%)$, and Transcendental domain $(n=6$, $3.5 \%$ ). The presence of dissonance is important because it has been shown to be associated with depression. According to Fisher (2014, p.71) people showing dissonance in two or more of the four domains of spiritual well-being (SWB) are described as being 'dissonants', and 'Spiritual dissonance, especially in Personal and Communal SWB, tends to relate to psychological depression.'

Comparisons of the domains in SHALOM with the dimensions in WELLHEAD have already been made on a theoretical level (Mumby \& Grace, 2019). The SHALOM lived experience (SWBQ) mean scores for each participant were compared with the overall mean of their WELLHEAD scores. There was a moderate correlation (Pearson's 0.645) suggesting that WELLHEAD reflected aspects of spiritual health in common with SHALOM. The Personal domain of SHALOM showed the highest correlations with the overall WELLHEAD score (Pearson's 0.747), followed by the Communal domain (0.608). These findings are interesting in light of Fisher's report of relationship between low scores in the Personal and Communal domains and depression in college students (Fisher, 2009). Conversely, the WELLHEAD dimension 'HIGH' showed the greatest correlation with the overall SHALOM lived experience (Pearson's 0.645). Some congruence between WELLHEAD and SHALOM was evident. For example, low 
WELLHEAD scores for PURPLE were consistent with the presence of dissonance detected in SHALOM, her narrative about 'seeking something real' and 'putting at ease some things in the past' and her readiness for further chaplaincy follow-up.

WELLHEAD encouraged people to score how far towards their ideal score of ' 10 ' they felt they were in each dimension, based on the interview exploration, so the scores captured lived experience relative to ideals rather than separating the two parameters as in SHALOM. The WELLHEAD 'HIGH' dimension appeared to elicit self-scores reflective of a broader definition of spirituality than encompassed by SHALOM, perhaps due to the inclusion of terms such as 'mystery', 'unknown', 'otherness' in addition to the theistic term 'God'. This breadth was illustrated in selfscores for 'HIGH' much higher proportionally than the Transcendental 'lived experience' score for those participants who were atheists or humanists (see RED, YELLOW, BROWN, Tables 5 and 6).

\section{Discussion}

The study showed WELLHEAD and SHALOM measured participant responses concerning their spirituality whilst exploring how and why they responded according to individual characteristics and circumstances, in the context of how they perceived the narrative process. Participant responses were fed back to them in a simple and structured way which facilitated their own thought processes concerning the complex area of spirituality. The sharing process promoted self-awareness using verbal thought processes usually curtailed in the context of their aphasia. This was linked to their perception that the session provided a catalyst for spiritual growth. These findings aligned with reports from Corsten, Schimpf, Konrad, Keilmann \& Harderings (2015), that biographic-narrative intervention influenced identity negotiation and quality of life in aphasia. WELLHEAD adopted narrative principles in exploring spirituality, providing the sort of intervention tool Corsten et al. called for, and addressing an overlooked aspect of identity and 'meaningfulness' (p798). Facilitation to use words gave legitimacy and acceptance of the deeper things in life.

Spirituality is a human trait, so any analysis carries bias from a human perspective, being by nature predominantly word-based and not mechanistic, concerning interpretation, reflexivity, understanding and the synthesis of evidence. To 
minimise bias from the PI about the participants' experiences, a systematic approach to analysis incorporated verification by the co-researcher, and weighed the validity and generalisability of interpretations. Direct involvement of the hospital chaplain as part of the research team was not approved by the Ethics Committee, but he offered general impartial advice in his role to 'all faiths and none', and he provided safeguarding to participants via onward referral. The high degree of reflexivity in the study increased the credibility of the findings. From before its onset, the course of the study was modified cyclically by the Steering group of people with aphasia (Mumby, in review). Member checking was used with participants at the time of data collection, immediately afterwards, and through two follow-up sessions, increasing the face validity of the analysis. The quantitative data offered some triangulation for the qualitative findings, and further in-depth (Phase 2 and 3) analysis about their relationship in individuals will be reported elsewhere.

Direct comparisons of the detailed WELLHEAD and SHALOM scores could not compare like with like as WELLHEAD asks participants to score themselves in relation to where they would like to be $(10 / 10)$ rather than in relation to a maximum score they perceive anyone could reach $(5 / 5)$ for lived experience. SHALOM's ideal score then reflects the harmony or dissonance between this ideal and their own lived experience, whereas WELLHEAD has the harmony or dissonance built in.

Nevertheless, the overall scores bear comparison across individuals as the overall focus in both is spiritual health and wellbeing. In designing further work it would be valuable to include SHALOM to permit statistical comparisons with other populations, and WELLHEAD as a means of focusing on identifying aspects of dimensions with the potential for spiritual growth, and on setting goals towards improved spiritual wellbeing. Domains scoring most dissonance, or dimensions having the lowest scores on WELLHEAD may actually require more growth than is possible in a single 'Next Step', as borne out in the examples of participants' goal-setting. Using SHALOM in a separate session from WELLHEAD (rather than separating them by a refreshment break) would help distinguish between assessment and intervention components, though this was beyond the scope of this study.

To address the research question of the feasibility of using these assessment resources with this inherently heterogenous patient population, an exploratory study 
design with a small number of participants was fully appropriate. Whilst the small sample size restricted the ability to make psychometric comparisons, the richness of the qualitative data confirmed the applicability of WELLHEAD and SHALOM. It is impossible to represent all world religions in a small sample from one location, but the intention to offer flexibility in WELLHEAD could be extended in future by introducing additional culture-specific pictures. Given the overwhelmingly positive response from participants concerning the structure of WELLHEAD (dimensions, words, pictures and starter questions) there is strong support for these resources being generic and transferable. The communication and cognitive accessibility of WELLHEAD makes it potentially suitable for other populations such as older people and those with mild dementia. Having established that the approach was suitable for those with aphasia, there is scope for wider application with participants who have other acquired or degenerative communication disorders including types of dysarthria, apraxia and mild cognitive-linguistic impairments. It is less likely to suit those with learning disability due to the graded nature of the resources and the use of the written word.

Excluding people with diagnosed mental health problems from the study may have resulted in the sample having lower incidence of depression than people with aphasia in general. Bearing in mind the known association of depression and low spiritual health scores, this exclusion may have been reflected in the relatively high SWBQ scores for participants compared with reports from other hospital populations. Nevertheless, the incidence of spiritual dissonance was relatively high, capturing an unresolved need. Future studies would benefit from including concomitant measures of mental health.

The format of WELLHEAD provided flexible yet replicable structures for conversations, with potential to offer pre- and post- intervention measures. The feedback analysis from WELLHEAD and SHALOM confirmed the potential for developing a larger study of people with aphasia, incorporating measures of spirituality and mental health (depression and anxiety) for investigating the effect of WELLHEAD. One crucial aspect was the 'safe place' provided by the interview context. WELLHEAD provided a flexible and unconditional environment for people to share about spirituality, and difficult experiences were 'held' jointly to allow them to be recognised, processed and for next steps to emerge. Spiritual health concerns finding 
meaning and purpose for living fully. 'Living successfully' with aphasia is a wellestablished term regarding adjustment to aphasia (Brown, Worrall, Davidson \& Howe, 2010; Brown et al. 2012; Grohn, Worrall Simmons-Mackie \& Hudson, 2014). 'Living fully', exemplified in participants' responses to WELLHEAD, differs in emphasis by encompassing both the positive and negative aspects of experience as part of spirituality.

\section{Conclusion}

Quantitative and qualitative evidence supported the feasibility of using WELLHEAD and SHALOM with people who had diverse world views and a wide range of aphasia. Such tools are important for understanding spiritual health as part of assessment intervention and evaluation. Participants valued supportive exploration of their spiritual health, which needs to be emphasized in the rehabilitation agenda.

\section{Word count including abstract 7486}

\section{Acknowledgements}

Revd. Capt. David Grace, Chaplain to Weston Area Health NHS Trust, UK, and Harvey Dymond, R\&D lead at the same Trust gave their support. The study was unfunded, but R\&D at Weston Area Health NHS Trust provided NVivo software.

All the Steering group members and hospital volunteers were invaluable, especially the participants with aphasia who have been such an inspiration.

Professor John Fisher is acknowledged for his gracious advice and expertise.

\section{Declaration of interest}

The authors report no conflict of interest. 


\section{References}

Berk, L., Bellinger, D., Koenig, H., Daher, N., Pearce, M., Robins, C...., \& King, M. (2015). Effects of Religious vs. Conventional Cognitive-Behavioral Therapy on Inflammatory Markers and Stress Hormones in Major Depression and Chronic Medical Illness: A Randomized Clinical Trial. Open Journal of Psychiatry, 5(3), 238-259. https://doi.org/10.4236/ojpsych.2015.53028.

Brown, K., Worrall, L., Davidson, B., \& Howe, T. (2010). Snapshots of success: An insider perspective on living successfully with aphasia. Aphasiology, 24 (10), 1267-1295, https://doi.org/10.1080/02687031003755429

Brown, K., Worrall, L., Davidson, B., \& Howe, T. (2012). Living successfully with aphasia: A qualitative meta-analysis of the perspectives of individuals with aphasia, family members, and speech-language pathologists. International Journal of Speech-Language Pathology, 14(2), 141-155, https://doi.org/ $10.3109 / 17549507.2011 .632026$

Campbell, J.D., Yoon, D.P., \& Johnstone, B., (2010). Determining relationships between physical health and spiritual experience, religious practices, and congregational support in a heterogeneous medical sample. Journal of Religion and Health, 49(1), 3-17.

Carey, L., \& Mathisen, B., (Eds.) (2018). Spiritual Care for Allied Health Practice: A Person-centered Approach. London and Philadelphia: Jessica Kingsley Publishers.

Corsten, S., Schimpf, E. J., Konradi, J., Keilmann, A., \& Hardering, F. (2015). The participants' perspective: how biographic-narrative intervention influences identity negotiation and quality of life in aphasia. International Journal of Language \& Communication Disorders, 50, 788-800. https://doi.org/10.1111/1460-6984.12173

Enderby, P., \& Alexandra John, (Eds.) 2015. Therapy Outcome Measures for Rehabilitation Professionals. Guildford: J\&R Press.

Fisher, J.W. (2009). Reaching the heart: Assessing and nurturing spiritual well-being via education. (EdD dissertation, University of Ballarat, Victoria, Australia). Available from https://researchonline.federation.edu.au:8080/vital/access/Handle $\underline{\text { Resolver/1959.17/42221 }}$ 
Fisher, J. (2010). Development and application of a spiritual well-being questionnaire called SHALOM. Religions. 1, 105-121.

Fisher, J. (2014). Importance of relating with God for spiritual wellbeing. (Doctoral dissertation). Available from Federation University, Ballarat, Australia: https://researchonline.federation.edu.au:8080/vital/access/HandleResolver/1959. $\underline{17 / 73747}$

Fisher, J. (2016). Selecting the best version of SHALOM to assess spiritual well-being. Religions, 7(45) doi:10.3390/rel7050045

Fleck, M. P., \& Skevington, S. M. (2007). Explaining the meaning of the WHOQOLSRPB. Revisita de Psiquiatria Clinica, 34(1), 67-69.

Gomez, R., \& Fisher, J. (2003). Domains of spiritual well-being and development and validation of the Spiritual Well-being Questionnaire. Personality and Individual Differences, 35, 1975-1991.

Grohn, B., Worrall, L., Simmons-Mackie, N., \& Hudson, K. (2014). Living successfully with aphasia during the first year post-stroke: A longitudinal qualitative study. Aphasiology, 28(12), 1405-1425 https://doi.org/10.1080/02687038.2014.935118.

de Jager Meezenbroek, E., Garssen, B., van den Berg, M. van Dierendonck, D. Visser A., \& Schaufeli, W. (2012). Measuring Spirituality as a Universal Human Experience: A Review of Spirituality Questionnaires". Journal of Religion and Health, 51, 336-54. https://doi.org/10.1007/s10943-010-9376-1.

Johnstone, B., Franklin, K.L., Yoon, D.P., Burris, J., \& Shigaki, C. (2008). Relationships among religiousness, spirituality, and health for Individuals with stroke. Journal of Clinical Psychology in Medical Settings, 15 (4) 308-313.

Koenig, H. G., (2012). Religion, Spirituality, and Health: The Research and Clinical Implications. International Scholarly Research Notices, Psychiatry, Article ID 278730, 33 pages. https://doi.org/10.5402/2012/278730.

Koenig, H. G., Boucher, N. A., O'Garo K. N., \& Pearce, M. (2016). Religiouslyintegrated Cognitive Behavioural Therapy for Major Depression in Chronic Medical Illness: Review of results from a Randomized Clinical Trial. Health and Social Care Chaplaincy, 4(2), 237-253. https://doi.org/10.1558/hscc.v4i2.31655 
Laures-Gore, J.S., Lambert, P.L., Kruger, A.C., Love, J. \& Davis, D.E. (2018).

Spirituality and Post-Stroke Aphasia Recovery. Journal of Religion and Health, 57, 1876-1888. https://doi.org/10.1007/s10943-018-0592-4

MacKenzie, S. (2016). Sacred Work? Exploring Spirituality with Therapists Working with Stroke Patients with Aphasia. Journal for the Study of Spirituality, 6(1), 7888. https://doi.org/10.1080/20440243.2016.1158457

Martin, A. S., Distelberg, B., Palmer, B. W., \& Jeste, D.V. (2015). Development of a new multidimensional individual and interpersonal resilience measure for older adults, Aging \& Mental Health, 19(1), 32-45. https://doi.org/10.1080/13607863.2014.909383

McSherry, W., \& Ross, L. (Eds.) (2010). Spiritual Assessment in Healthcare Practice. Cumbria: M\&K Publishing.

Monod S., Brennan M., Rochat, E. T., Martin, E., Rochat, S., \& Bula, C.J. (2011). Instruments Measuring Spirituality in Clinical Research: A Systematic Review. Journal of General Internal Medicine, 26(11), 1345-57. https://doi.org/10.1007/s11606-011-1769-7

Morris, R., Eccles, A., Ryan, B., \& Kneebone, I. (2017). Prevalence of anxiety in people with aphasia after stroke. Aphasiology, 31(12), 1410-1415. https://doi.org/10.1080/02687038.2017.1304633.

Mumby K., \& Whitworth A. (2013). Adjustment processes in chronic aphasia after stroke: Exploring multiple perspectives in the context of a community based intervention. Aphasiology, 27(4), 462-489. https://doi.org/10.1080/02687038.2013.772559

Mumby K. and Hobbs E. (2017). 'The Shape of Discipleship' The Reader, 117(1), 1617. Available from https://www.readers.cofe.anglican.org/u d lib pub/m1171.pdf

Mumby, K. (2018). WELLHEAD Resources. Information available from: http://wellhead.org.uk

Mumby, K. (2019). A single case narrative of spirituality following aphasia from traumatic brain injury: Findings about forgiveness and freedom using WELLHEAD and SHALOM. Religions, 10, 301. https://doi.org/10.3390/rel10050301 
Mumby, K. \& Grace, D. (2019). Introducing WELLHEAD: Reflecting on a collaborative approach to spiritual assessment and intervention, developed with people with aphasia. Health and Social Care Chaplaincy 7(2). http://dx.doi.org/10.1558/hscc.37004

Mumby, K. (in review 2019). People with aphasia shape spirituality research: Unlocking insights into access and acceptability.

Nolan, S. (2014). Chaplaincy Outcomes - What the Future Looks Like? Journal of Health and Social Care Chaplaincy, 2(2), 161-164.

Puchalski, C., Ferrell, B., Virani, R., Otis-Green, S., Baird, P., Bull, J., Chochinov, H., Handzo, G., Nelson-Becker, H., Prince-Paul, M., Pugliese, K., \& Sulmasy, D. (2009). Improving the Quality of Spiritual Care as a Dimension of Palliative Care: The Report of the Consensus Conference. Journal of Palliative Medicine 12(10), 885-904. https://doi.org/10.1089=jpm.2009.0142

Riklikiene, O., Kaseliene, S., \& Fisher, J. (2018). Translation and Validation of Spiritual Well-Being Questionnaire SHALOM in Lithuanian Language, Culture and Health Care Practice. Religions, 9, 156. https://doi.org/10.3390/re19050156

Sawatsky, R., Ratner, P.A., \& Chiu L. (2005). A Meta-Analysis of the relationship between Spirituality and Quality of Life. Social Indicators Research, 72(2), 153188.

Skevington, S. M., Gunson, K. S., \& O’Connell, K. A. (2013). Introducing the WHOQOL-SRPB BREF: developing a short-form instrument for assessing spiritual, religious and personal beliefs within quality of life. Quality of Life Research, 22(5), 1073-1083.

Swinton, J. (2001). Spirituality and Mental Health Care: Rediscovering a forgotten dimension. London: Jessica Kingsley Publishers Ltd.

Wray, F., \& Clarke, D. (2017). Longer-term needs of stroke survivors with communication difficulties living in the community: a systematic review and thematic synthesis of qualitative studies. BMJ Open, 7, e017944. https://doi.org/10.1136/ bmjopen-2017-017944 
Appendix A Feedback questionnaire (Provided in large font and read aloud with participants to underpin the feedback interview)

- Were you comfortable with the materials (pictures, words)?

Yes/Don't know/No

- Was there anything that made you uncomfortable?

- Were the questions easy to understand?

Yes/Don't know/No

- Was the right amount of time allowed?

Yes/Don't know/No

- Did it help you think?

- What was the best part?

Yes/Don't know/No

o What was the worst part?

- Would you like to do more in a similar way?

Yes/Don't know/No

- Will you do anything as a result?

Yes/Don't know/No

If so what? 
Appendix B SHALOM Mean Lived Experience (SWBQ) findings in people with aphasia compared with other populations

\begin{tabular}{|l|l|l|l|l|}
\hline & PERSONAL & COMMUNAL & ENVIRONMENTAL & TRANSCENDENTAL \\
\hline CANCER & 3.1 & 3.47 & 3.25 & 3.66 \\
\hline (Fisher 2016) & & 2.37 & 2.39 & 2.4 \\
\hline RENAL & 2.43 & & & \\
\hline (Fisher 2016) & & & & \\
\hline $\begin{array}{l}\text { APHASIA } \\
\text { (This study) }\end{array}$ & 4.12 & 4.26 & & \\
\hline
\end{tabular}

